УДК 632.928

\title{
ДИНАМИКА И РАЗЛИЧИЯ В КОНЦЕНТРАЦИИ ОСНОВНЫХ ФОТОСИНТЕТИЧЕСКИХ ПИГМЕНТОВ ЛИСТЬЕВ БЕРЕЗЫ, ПРОИЗРАСТАЮЩЕЙ В НЕОДНОРОДНЫХ УСЛОВИЯХ
}

\section{() М.Э. Баландайкин}

\author{
Ульяновский государственный университет, ул. Л. Толстого, 42, Ульяновск, \\ 432017, (Россия), e-mail: 131119892007@rambler.ru
}

Обсуждается комплекс особенностей влияния внешних факторов на структуру основных фотосинтетических пигментов листовой пластинки березы. Кроме того, показана специфика воздействия инфекционного патологического стресс-фактора - ксилотрофного базидиального макромицета (факультативного сапротрофа) трутовика скошенного на содержание хлорофиллов типа $a, b$, их суммы, каротиноидов, соотношения пигментов в листовых пластинах деревьев Betula pendula Roth.

Ключевые слова: Inonotus obliquиs (Pers.: Fr.) Pilat, Betula pendula Roth., пигменты.

\section{Введение}

Процессы диссимиляции (дыхания) в растении неразрывно связаны с процессами ассимиляции (фотосинтеза). Как и любая физиологическая функция, фотосинтез приспособлен к сочетанию тех условий, в которых этот процесс осуществляется, от которых зависит его течение. Это проявляется прежде всего в наличии и особенностях хлорофилла, в свойствах его структурных элементов. Любое, в том числе и патологическое, нарушение фотосинтеза связано в первую очередь с количественными и качественными изменениями в пигментном аппарате зеленого растения [1].

В специальной научной литературе имеются отдельные сведения о влиянии некоторых природных факторов на динамику накопления пигментов фотосинтеза в активно ассимилирующем аппарате.

О нарушении процесса фотосинтеза у инвазированного растения отмечают в работах [1-7]. Эти исследователи указывают, что чаще всего у инфицированных деревьев происходит значительное снижение интенсивности фотосинтеза. Снижение фотосинтетической активности пораженных болезнью растений исследователи объясняют разными причинами. М.Н. Родигин [8], Т.Д. Страхов [9], Н.А. Черемисинов [10] и другие считают, что снижение энергии фотосинтеза вследствие инфекции грибами связано в одних случаях с отмиранием и выпадением части ассимиляционного аппарата, в других - с действием экстрацеллюлярных ферментов и продуктов их гидролитической активности на живые клетки питающего растения. По мнению других исследователей [11, 12], одной из причин снижения фотосинтеза при поражении растений патогенными грибами является уменьшение количества хлорофилла в листьях больного растения. С.А. Тарр [13], П.И. Юшков [14] считают, что подавление фотосинтеза при некоторых болезнях происходит не только из-за нарушения в пигментном аппарате и глубинных изменений в ходе темновых реакций, но и из-за нарушения оттока ассимилянтов из листьев в запасающие органы.

Вопрос о влиянии инфекционных болезней на содержание каротиноидов проработан недостаточно. Например, по мнению П.Дж. Аллена [15], каротиноиды подвержены разрушению в меньшей степени, чем

Баландайкин Михаил Эдуардович - аспирант кафедры лесного хозяйства экологического факультета института медицины, экологии и физической культуры, e-mail: 131119892007@ rambler.ru хлорофилл. По данным Б.А. Рубина [16], при поражении растений некоторыми грибами наблюдается даже некоторое повышение содержания каротина в листьях. Как считает этот автор, данный пигмент синтезируется самими паразитами. 
Авторы $[1,5,17]$ отмечают значительные пределы изменчивости интенсивности фотосинтетической деятельности деревьев в течение суток и вегетационного периода. По их мнению, это объясняется тем, что данный процесс зависит от комплекса многих факторов: интенсивности освещения, температуры воздуха, концентрации $\mathrm{CO}_{2}$ в атмосфере, состояния деревьев и др.

Экологическая пластичность, свойственная листовому аппарату, проявляется в изменении его компонентного состава и функциональной активности в зависимости от комплекса биотопических условий (особенности светового, гидротермического, эдафического и прочих режимов). Важно отметить, что в зависимости от экзогенных условий обнаруживаются адаптивные изменения на уровне метаболических процессов либо тканевого строения. В работе [18] показано изменение содержания фотосинтетических пигментов в листьях березы в зависимости от месяца вегетационного периода. Максимум содержания пигментов авторами отмечен в июне - июле, к августу оно стало вдвое меньше, к сентябрю достигло одной четвертой - одной шестой части от сезонного максимума. По данным [18-21], изменчивость погодных условий весны/осени в разные годы определяет различную скорость формирования и деградации пигментного аппарата, тогда как середина вегетационного периода, как правило, демонстрирует определенную стабилизацию картины. Уровень содержания фотосинтетических пигментов наиболее изменчив в молодых листьях и опаде, что делает нецелесообразным проведение оценки пигментного аппарата до достижения листовыми пластинками полной зрелости или после начала осеннего изменения окраски листьев.

Следует также особо обратить внимание на то, что содержание хлорофилла в листьях верхнего яруса наиболее высокое по сравнению с аналогичным показателем ассимиляционного аппарата нижнего полога, поскольку листья верхней части крон деревьев первого яруса поглощают значительную часть экспонируемой длинноволновой радиации, которая обладает максимальной активностью.

Влияние автотранспортных атмосферных эмиссий (поллютантов) на лесные экологические системы в ряде районов нашей страны иногда может быть существенным. Эмитенты выбрасывают в атмосферу весьма обширный спектр аэроксенобиотиков: это и смесь газов, паров и твердых частиц, в состав которых входят разнообразные химические вещества. Лучше всего изучено влияние на древесные растения кислых газов, особенно сернистого ангидрида (двуокиси серы). Он парализует процесс фотосинтеза, что приводит, согласно исследованиям Н.П. Красинского [22], к фотодинамическому действию хлорофилла - окислению стромы, а затем и всего содержимого хлорофиллового зерна. По сообщению А.И Воронцова [23], под влиянием промышленных газов происходит подавление фотосинтеза, нарушение водообмена и многих биохимических процессов, снижение транспирации, общее угнетение роста и развития древесных пород.

О.А. Неверова [24] также считает, что многие физиологические процессы у зеленых растений обладают высокой чувствительностью к промышленным загрязнителям, и фотосинтез не является исключением. По сведениям этого автора, кислые газы вызывают вначале слабое подавление, затем активацию и далее устойчивое подавление фотосинтеза. Многие газы оказывают влияние на ферменты фотосинтетического цикла и дыхания. Например, имеются сведения, согласно которым под влиянием низких доз $\mathrm{SO}_{2}$ и $\mathrm{HF}$ стимулируется пигментообразование, а высокие концентрации данных газов приводят к снижению содержания хлорофилла, что может быть следствием разрушения хлорофиллов и превращения их в соответствующие феофитины, а также уменьшения синтеза хлорофилла. Отмечается, что хлорофилл типа $a$ и каротиноиды более чувствительны к промышленным выбросам, чем хлорофилл $b$ [24]. Авторы [25] обнаружили двухфазный характер зависимости содержания основных пигментов фотосинтеза в листовом аппарате березы повислой от уровня автотранспортной нагрузки.

Цель работы - оценка и изучение специфики воздействия ряда абиотических и биотических факторов окружающей природной среды на интенсивность процессов фотосинтетической системы листовых пластин березы.

\section{Экспериментальная часть}

Содержание основных фотосинтетических пигментов в листовых пластинах березы определялось по методике, представленной в [26]. Плотность экстракта на спектрофотометре измерялась при длинах волн, соответствующих максимумам поглощения хлорофиллов $a$ и $b$ в красной области спектра - 663, 644 нм соответственно и при длине волны абсорбционного максимума каротиноидов - 452,5 нм. Концентрации пигментов рассчитывались по Реббелену. 
Математический анализ полученных в ходе исследований данных осуществлялся в соответствии с принципами и методологией теории вероятностей и математической статистики [27-30].

\section{Обсуждение результатов}

Содержание основных фотосинтетических пигментов листового аппарата семи различных вариантов опыта и совокупности, которая представляет здоровую березу повислую, произрастающую в насаждении, показано на рисунке 1.

Рисунок 2 отображает эмпирическое отношение концентраций хлорофиллов $a$ и $b$, а также отношение общего содержания хлорофиллов $a, b$ к суммарной концентрации каротиноидов в листьях деревьев всех анализируемых экспериментальных совокупностей.

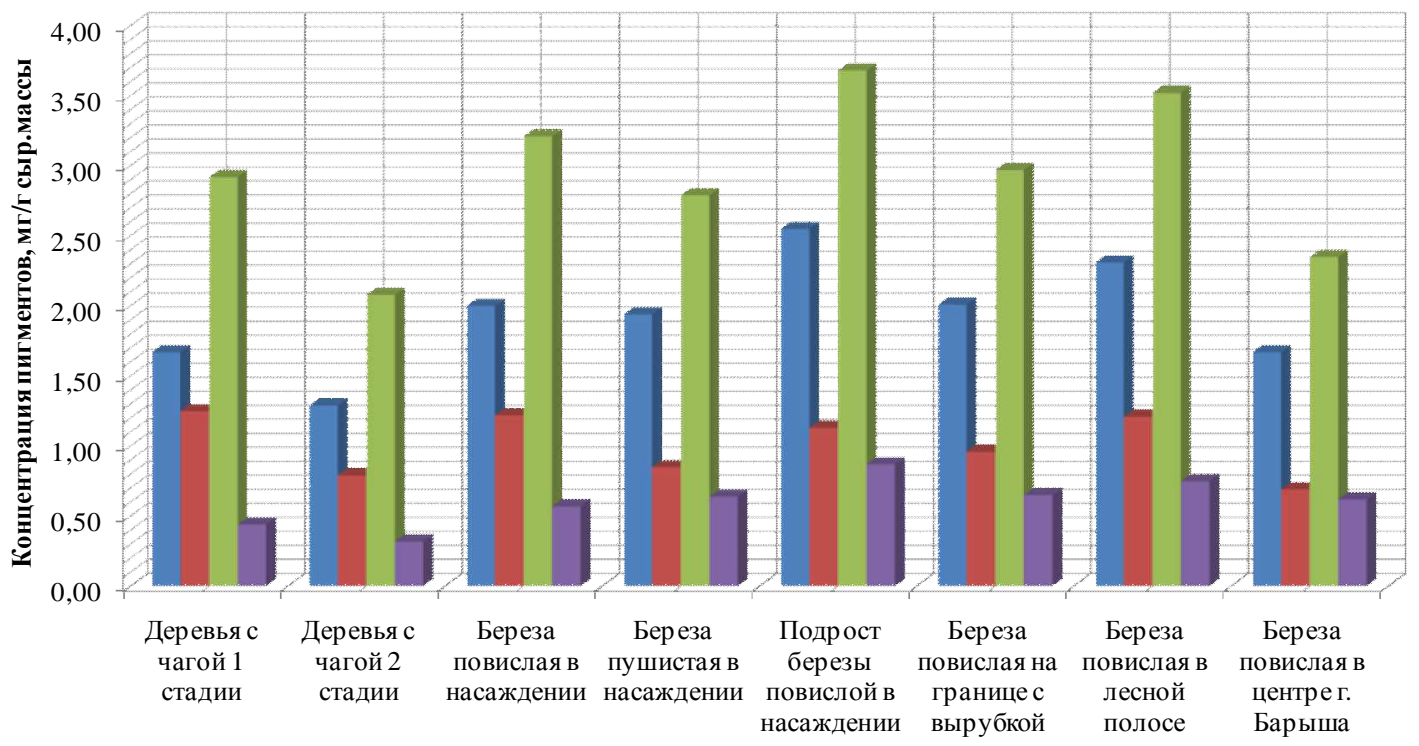

Рис. 1. Состав пигментов фотосинтеза в листовых пластинках березы, произрастающей в различных биотопах: - хлорофилл $a, \square-$ хлорофилл $b, \square-$ хлорофилл $a+$ хлорофилл $b, \square-$ каратиноиды

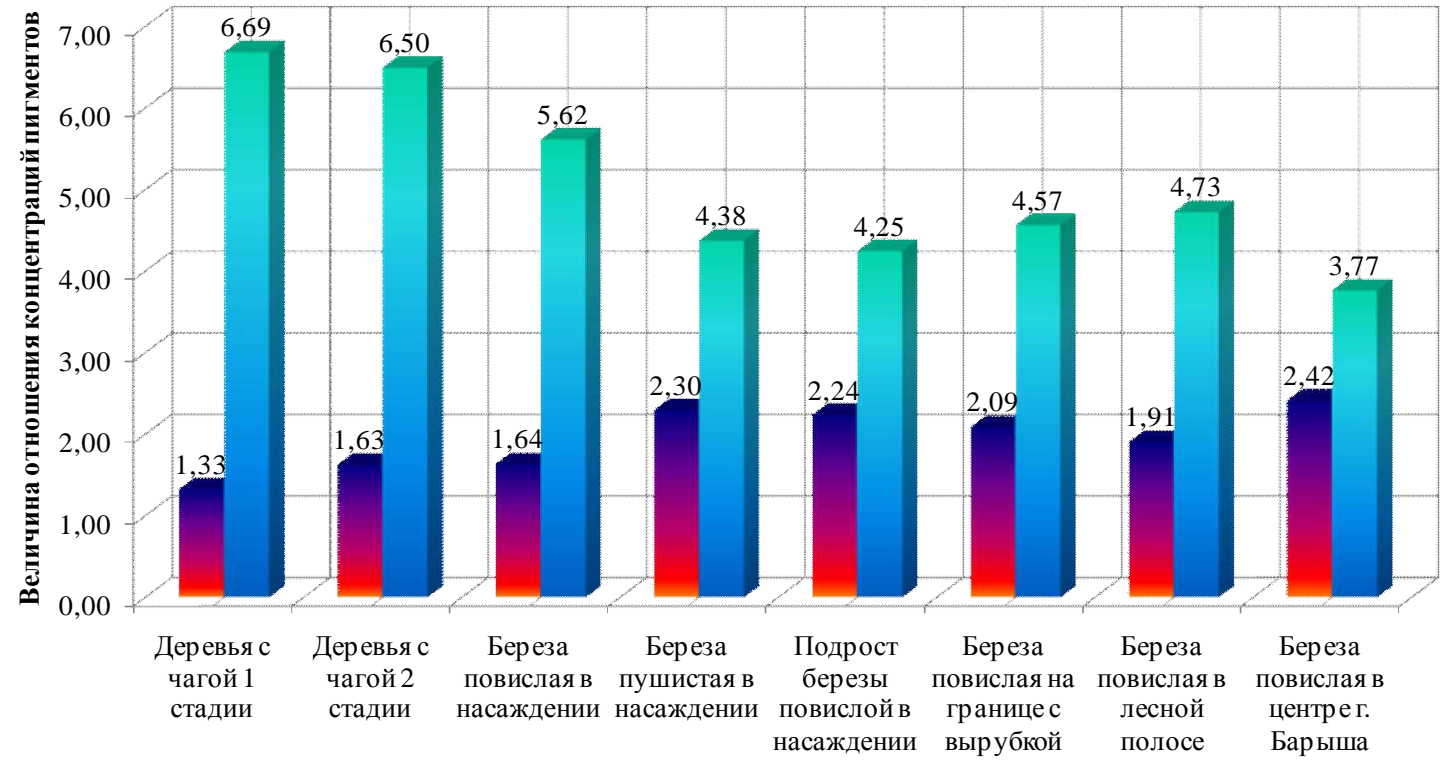

Рис. 2. Отношение концентраций хлорофиллов $a$ и $b$, а также отношение общего содержания хлорофиллов $a, b$ к суммарной концентрации каротиноидов в листьях. - хлорофилл $a$ / хлорофилл $b$; - хлорофилл $a+$ хлорофилл $b$ / каратиноиды 
У подроста березы повислой $\left(C_{x л . a}=2,55 \pm 0,05\right.$ мг/г сырой массы), деревьев с чагой на второй условной стадии развития $\left(C_{x л . a}=1,29 \pm 0,10\right.$ мг/Г сырой массы), деревьев, произрастающих в центральной части Барыша, с преобладанием аэрополлютантов в составе техногенных эмиссий $\left(C_{x л . a}=1,67 \pm 0,05\right.$ мг/Г сырой массы), и березы повислой, формирующей полезащитную лесную полосу $\left(C_{x л . a}=2,31 \pm 0,05\right.$ мг/Г сырой массы), концентрация хлорофилла типа $a$ в листовых пластинах статистически значимо отличается от данного показателя здоровой березы повислой из насаждения $\left(C_{x л . a}=2,00 \pm 0,04\right.$ мг/г сырой массы).

По содержанию хлорофилла $b$ в листьях со здоровой повислой березой, произрастающей в насаждении $\left(C_{x л . b}=1,22 \pm 0,05\right.$ мг/Г сырой массы), достоверно различаются деревья из центра города Барыша $\left(C_{x л . b}\right.$ $=0,69 \pm 0,03$ мг/г сырой массы) и деревья, инвазированные I. obliquus и имеющие чагу 2 ст. $\left(C_{x л . b}=0,79 \pm 0,07\right.$ мг/г сырой массы). Также статистически подтверждаются и различия между этими двумя категориями деревьев и здоровой березой повислой из насаждения $\left(C_{x л . a+b}=3,21 \pm 0,08\right.$ мг/г сырой массы) в суммарной концентрации хлорофиллов $a$ и $b . C_{x л . a+b}$ в листовых пластинах деревьев, которые находятся в центре Барыша,

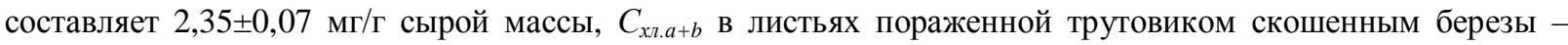

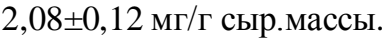

Как показывают результаты испытаний, наибольшую концентрацию хлорофилла $a$ в листовых пла-

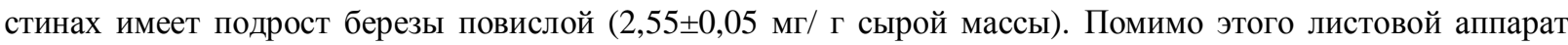
подроста березы повислой характеризуется и самой высокой $C_{\kappa a p . ~}(0,87 \pm 0,03$ мг/Г сырой массы), а также максимальным суммарным содержанием хлорофиллов (3,68 $\pm 0,07$ мг/ г сырого веса). Если исходить из данных рисунка 1, здоровая береза повислая, произрастающая в лесонасаждении, отличается меньшими величинами $C_{x л . a}, C_{x л . a+b}$ и $C_{\text {кар. }}$ в листовых пластинах по сравнению с подростом, что, вполне вероятно, является следствием различной требовательности березы повислой к свету на разных стадиях онтогенеза.

Концентрации основных фотосинтетических пигментов в листьях, а также отношение концентраций хлорофиллов и каротиноидов деревьев, произрастающих в лесной полосе, превосходят аналогичные показатели листового аппарата березы повислой, расположенной на границе насаждения с вырубкой (рис. 1 и 2). В данном контексте особенно важно обозначить, что для березы повислой свет является лимитирующим фактором, поскольку она относится к типичным гелиофилам.

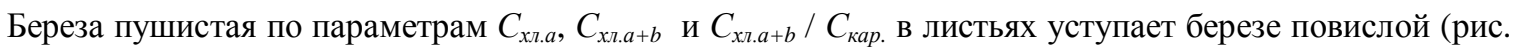
1, 2). По-видимому, это объясняется спецификой эдафических условий, менее подходящих для произрастания B. pubescens. В данном биотопе присутствуют свежие почвы - А2, тогда как пушистая береза предпочитает гигрофильные условия.

В серии сравниваемых выборок береза повислая из центральной части Барыша и пораженные трутовиком скошенным экземпляры деревьев с чагой на первой условной стадии развития отличаются крайне

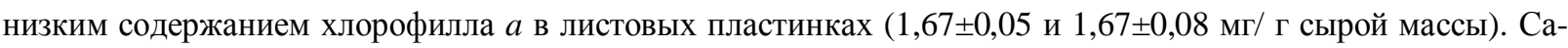
мой низкой концентрацией хлорофилла $а$ в листьях характеризуются инвазированные деревья березы по-

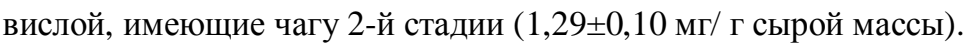

В листьях деревьев с чагой, находящейся на 2 ст., самые низкие из всех рассматриваемых выборок $C_{x л . a}, C_{x л . а+b}$ и $C_{\text {кар. }}$ (соответственно $1,29 \pm 0,10,2,08 \pm 0,12$ и 0,32 $\pm 0,09$ мг/г сырой массы). По содержанию (дефициту) хлорофилла b в листовом аппарате инфицированные трутовиком скошенным деревья, на которых чага достигла 2-й стадии развития, уступают лишь березе, расположенной в центре Барыша. По нашему мнению, в результате инфицирования трутовиком скошенным березы осуществляется нарушение водного и минерального питания растущих деревьев, изменяется ферментативная активность, происходит ослабление фотосинтеза. Последнее, по выражению Н.И. Федорова [5], оказывает влияние на весь сбалансированный ритм нормальных физиологических процессов зараженных деревьев. При гнилевом заболевании, вызванном ксилотрофным макромицетом I. obliquus, вероятно, также наблюдаются изменения обмена веществ, в первую очередь белков и углеводов. Все это в конечном итоге способствует нарушению процессов образования пластид. Снижение уровня содержания основных фотосинтетических пигментов в листьях растений, подвергшихся воздействию ксенобиотиков, подтверждается сведениями, содержащимися в ряде работ [25, 31].

\section{Bblводbl}

1. Снижение уровня содержания хлорофиллов и каротиноидов в листовых пластинах можно рассматривать как нарушение функционирования фотосинтетического аппарата, а значит, дестабилизацию гомеостаза дерева. 
2. Результаты эксперимента свидетельствуют о том, что из основных пигментов фотосинтеза наибольшей стабильностью обладает хлорофилл $a$.

3. При неспецифическом и интегрированном действии разнородных эколого-биологических факторов на березу в ее листовых пластинах снижение $C_{x л . a}$, проходит соразмерно с увеличением тяжести стресса у растительного организма.

\section{Список литературы}

1. Чураков Б.П. Взаимоотношения патогенных грибов с древесными растениями. М., 1993. 195 с.

2. Журавлев И.И. Диагностика болезней леса. М., 1962. 192 с.

3. Смирнова В.К., Завьялова Н.С. Влияние сосновой губки на некоторые физиолого-биохимические показатели у сосны // Развитие лесообразующего процесса на Урале. Вып. 105. Свердловск, 1977. С. 132-137.

4. Федоров Н.И. Сезонная и возрастная динамика содержания хлорофилла в хвое сосны, пораженной корневой губкой // Лесовед. и лесн. хоз-во. 1969. Вып. 1. С. 39-44.

5. Федоров Н.И. Корневые гнили хвойных пород. М., 1984. 160 с.

6. Федоров Н.И., Воронкова Н.Г. Сезонная и возрастная динамика содержания хлорофилла в хвое сосны, пораженной смоляным раком // Ботаника. Минск, 1969. Вып. 11. С. 41-46.

7. Федоров Н.И., Воронкова Н.Г. Содержание пигментов в хвое сосны, пораженной смоляным раком // Ботаника (исследования): сб. ст. / под ред. И.Д. Юркевича. Минск, 1969. Вып. 11. С. 135-141.

8. Родигин М.Н. Общая фитопатология. М., 1978. 365 с.

9. Страхов Т.Д. Введение в общую фитопатологию. Киев, 1962. 172 с.

10. Черемисинов Н.А. Общая патология растений. М., 1973. 352 с.

11. Кокин А.Я., Тумариксон Х.С. Физиологическое обоснование вредоносности ржавчины овса // Труды по защите растений. 1934. Вып. 6. С. 11-34.

12. Рубин Б.А., Арциховская Е.В. Биохимия и физиология иммунитета растений. М., 1968. 412 с.

13. Тарр С.А. Основы патологии растений. М., 1975. 269 с.

14. Юшков П.И. Распределение продуктов фотосинтеза в сосне // Физиология и экология древесных растений: труды Института экологии. Свердловск, 1965. Вып. 43. С. 17-23.

15. Аллен П.Дж. Обмен веществ при облигатном паразитизме // Проблемы и достижения фитопатологии. М., 1962. C. $126-139$.

16. Рубин Б.А. Курс физиологии растений. М., 1961. 583 с.

17. Чураков Б.П., Чураков Д.Б. Фитопатология. М., 2007. 424 с.

18. Кавеленова Л.М., Малыхина Е.В., Розно С.А., Смирнов Ю.В. К методологии экофизиологических исследований листьев древесных растений // Поволжский экологический журнал. 2008. №3. С. 200-210.

19. Кавеленова Л.М. Проблемы организации системы фитомониторинга городской среды в условиях лесостепи. Самара, 2006. 222 с.

20. Кавеленова Л.М., Лищинская С.Н., Карандаева Л.Н. Особенности сезонной динамики водорастворимых фенольных соединений в листьях березы повислой в условиях урбосреды // Химия растительного сырья. 2001. №3. С. 91-96.

21. Кавеленова Л.М., Розно С.А., Киреева Ю.В., Смирнов Ю.В. К структурно-функциональным особенностям листьев древесных растений в насаждениях лесостепи // Самарская Лука : бюллетень. 2007. Т. 16. №3 (21).C. 568-574.

22. Красинский Н.П. Теоретические основы построения ассортиментов газоустойчивых растений // Сборник работ Академии коммунального хозяйства и Горьковского государственного университета. М.; Горький, 1950. С. 3-140.

23. Воронцов А.И. Патология леса. М., 1978. 272 с.

24. Неверова О.А. Применение фитоиндикации в оценке загрязнения окружающей среды // Биосфера. 2009. Т. 1, №1. C. 82-92.

25. Ерофеева Е.А., Сухов В.С., Наумова М.М. Двухфазная зависимость некоторых эколого-морфологических и биохимических параметров листовой пластинки березы повислой от уровня автотранспортного загрязнения // Поволжский экологический журнал. 2009. №4. С. 288-295.

26. Третьяков Н.Н. Практикум по физиологии растений. М., 1990. 271 с.

27. Гланц С. Медико-биологическая статистика. М., 1998. 459 с.

28. Лакин Г.Ф. Биометрия. М., 1990. 352 с.

29. ГОСТ 8.207-76. Прямые измерения с многократными наблюдениями. Методы обработки результатов измерений. М., 1976. 8 с.

30. Чупахина Г.Н. Физиологические и биохимические методы анализа растений. Калининград, 2000. 59 с.

31. Колмогорова Е.Ю. Реакция пигментного комплекса древесных растений на загрязнение атмосферного воздуха выбросами автотранспорта // Экологические проблемы промышленных городов: сборник научных трудов. Саратов, 2009. Ч. 1. С. 162-164. 


\section{Balandaykin M.E. DYNAMICS AND DISTINCTIONS IN CONCENTRATION OF THE BASIC PHOTOSYNTHET- IC PIGMENTS OF LEAVES OF THE BIRCH GROWING IN IMPURE CONDITIONS}

Ulyanovsk State University, L. Tolstogo st., 42, Ulyanovsk, 432017 (Russia), e-mail: $131119892007 @$ rambler.ru

The complex of features of influence of external factors on frame of the basic photosynthetic pigments of a sheet plate of a birch is discussed. Besides, specificity of influence of the infectious pathological stress-factor - xylotroph basidial macromycet (facultative saprotroph) a tinder fungus bevelled - on the content of a chlorophyll of phylum a, b, their sums, lipochromes, an interrelation of pigments in sheet plates of trees Betula pendula Roth. is shown.

Keywords: Inonotus obliquus (Pers.: Fr.) Pilat, Betula pendula Roth., pigments.

\section{References}

1. Churakov B.P. Vzaimootnosheniia patogennykh gribov s drevesnymi rasteniiami. [Pathogenic fungi relationship with woody plants]. Moscow, 1993,195 p. (in Russ.).

2. Zhuravlev I.I. Diagnostika boleznei lesa. [Diagnosis of diseases of forest.]. Moscow, 1962, 192 p. (in Russ.).

3. Smirnova V.K., Zav'ialova N.S. Razvitie lesoobrazuiushchego protsessa na Urale. [Development of forest formation in the Urals.]. Sverdlovsk, 1977. no. 105, pp. 132-137. (in Russ.).

4. Fedorov N.I. Lesovedenie i lesnoe khoziaistvo, 1969, no. 1, pp. 39-44. (in Russ.).

5. Fedorov N.I. Kornevye gnili khvoinykh porod. [Root rot conifers.]. Moscow, 1984, 160 p. (in Russ.).

6. Fedorov N.I., Voronkova N.G. Botanika (issledovaniia). Ed. I.D. Jurkevich.]. [Botany (study): Collection of articles.]. Minsk, 1969, no. 11, pp. 41-46. (in Russ.).

7. Fedorov N.I., Voronkova N.G. Botanika (issledovaniia). Ed. I.D. Jurkevich.]. [Botany (study): Collection of articles.]. Minsk, 1969, no. 11, pp. 135-141. (in Russ.).

8. Rodigin M.N. Obshchaia fitopatologiia. [General Phytopathology.]. Moscow, 1978, 365 p. (in Russ.).

9. Strakhov T.D. Vvedenie v obshchuiu fitopatologiiu. [Introduction to the general Phytopathology.]. Kiev, 1962,172 p. (in Russ.).

10. Cheremisinov N.A. Obshchaia patologiia rastenii. [General pathology of plants.]. Moscow, 1973, 352 p. (in Russ.).

11. Kokin A.Ia., Tumarikson Kh.S. Trudy po zashchite rastenii, 1934, no. 6, pp. 11-34. (in Russ.).

12. Rubin B.A., Artsikhovskaia E.V. Biokhimiia i fiziologiia immuniteta rastenii. [Biochemistry and physiology of plant immunity.]. Moscow, 1968, 412 p. (in Russ.).

13. Tarr S.A. Osnovy patologii rastenii. [Fundamentals of Plant Pathology.]. Moscow, 1975, 269 p. (in Russ.).

14. Iushkov P.I. Fiziologiia i ekologiia drevesnykh rastenii: trudy Instituta ekologii. [Physiology and ecology of woody plants: proceedings of the Institute of Ecology.]. Sverdlovsk, 1965, no. 43, pp. 17-23. (in Russ.).

15. Allen P.Dzh. Problemy $i$ dostizheniia fitopatologii. [Challenges and achievements of Phytopathology.]. Moscow, 1962, pp. 126-139. (in Russ.).

16. Rubin B.A. Kurs fiziologii rastenii. [Rates of Plant Physiology.]. Moscow, 1961, 583 p. (in Russ.).

17. Churakov B.P., Churakov D.B. Fitopatologiia. [Phytopathology.]. Moscow, 2007, 424 p. (in Russ.).

18. Kavelenova L.M., Malykhina E.V., Rozno S.A., Smirnov Iu.V. Povolzhskii ekologicheskii zhurnal, 2008, no. 3, pp. 200-210. (in Russ.).

19. Kavelenova L.M. Problemy organizatsii sistemy fitomonitoringa gorodskoi sredy v usloviiakh lesostepi. [Problems of organization system phytomonitoring urban environment under forest.]. Samara, 2006, 222 p. (in Russ.).

20. Kavelenova L.M., Lishchinskaia S.N., Karandaeva L.N. Khimiia rastitel'nogo syria, 2001, no. 3, pp. 91-96. (in Russ.).

21. Kavelenova L.M., Rozno S.A., Kireeva Iu.V., Smirnov Iu.V. Biulleten' «Samarskaia Luka», 2007, vol. 16, no. 3, (21). pp. 568-574. (in Russ.).

22. Krasinskii N.P. Sbornik rabot Akademii kommunal'nogo khoziaistva i Gor'kovskogo gosudarstvennogo universiteta. [Collected works of the Academy of Municipal Economy and Gorky State University.]. Moscow; Gor'kii, 1950, pp. 3-140. (in Russ.).

23. Vorontsov A.I. Patologiia lesa. [Pathology forest.]. Moscow, 1978, 272 p. (in Russ.).

24. Neverova O.A. Biosfera, 2009, vol. 1, no. 1, pp. 82-92. (in Russ.).

25. Erofeeva E.A., Sukhov V.S., Naumova M.M. Povolzhskii ekologicheskii zhurnal, 2009, no. 4, pp. 288-295. (in Russ.).

26. Tret'iakov N.N. Praktikum po fiziologii rastenii. [Workshop on plant physiology.]. Moscow, 1990, 271 p. (in Russ.).

27. Glants S. Mediko-biologicheskaia statistika. [Biomedical statistics.]. Moscow, 1998, 459 p. (in Russ.).

28. Lakin G.F. Biometriia, [Biometrics.]. Moscow, 1990, 352 p. (in Russ.).

29. GOST 8.207-76. Priamye izmereniia s mnogokratnymi nabliudeniiami. Metody obrabotki rezul'tatov izmerenii. [State Standard 8.207-76. Direct measurements with multiple observations. Methods of processing measurement results.]. Moscow, 1976, 8 p. (in Russ.).

30. Chupakhina G.N. Fiziologicheskie i biokhimicheskie metody analiza rastenii. [Physiological and biochemical methods of plant analysis.]. Kaliningrad,2000, 59 p. (in Russ.).

31. Kolmogorova E.Iu. Ekologicheskie problemy promyshlennykh gorodov: sbornik nauchnykh trudov. [Ecological problems of industrial cities: collection of scientific papers.]. Saratov, 2009, part 1, pp. 162-164. (in Russ.). 